\title{
Utilizing eLearning to strengthen the capacity of global health practitioners and institutions around the world
}

\author{
Lisa Mwaikambo* \\ Center for Communication Programs \\ Johns Hopkins University, USA \\ E-mail: lbasalla@jhuccp.org
}

\section{Megan Avila}

Center for Communication Programs

Johns Hopkins University, USA

E-mail: mega.o.avila@gmail.com

\section{Sara Mazursky}

Center for Communication Programs

Johns Hopkins University, USA

E-mail: smazursk@jhuccp.org

\section{Kavitha Nallathambi}

Center for Communication Programs

Johns Hopkins University, USA

E-mail: knallath@jhuccp.org

*Corresponding author

\begin{abstract}
This paper presents eLearning as a solution for strengthening human resources for health as well as organizational capacity of regional and local nongovernmental organizations in developing countries. Building the knowledge base and increasing opportunities for continuous learning are crucial ways to strengthen the workforce and health systems in developing countries. In this paper, the authors describe the success of the Global Health eLearning $(\mathrm{GHeL})$ Center and share findings from its multi-phased evaluation. As a result of this successful experience, the Knowledge for Health (K4Health) Project, based at Johns Hopkins Bloomberg School of Public Health's Center for Communication Programs (JHU.CCP), implemented three unique country level eLearning programs that seek to improve the knowledge and skills of targeted local audiences as well as build the organizational capacity of the incountry partner organizations in delivering effective eLearning programs. The authors describe the unique applications of each, a variety of ways employed to overcome issues of access, and their lessons learned.
\end{abstract}

Keywords: eLearning; Technology-enabled learning; Knowledge sharing; Capacity building; Monitoring and evaluation

Biographical notes: Lisa Mwaikambo is an eLearning Coordinator with the 
K4Health Project based at Johns Hopkins University Center for Communication Programs. She is a certified Knowledge Manager and has a Master of Public Health with a concentration in Adolescent and Reproductive Health from Case Western Reserve University.

Megan Avila is Project Manager of the Agency for Healthcare Research and Quality's (AHRQ) Excellence in Obstetrics Grant awarded to Ascension Health She also works as a consultant to the Knowledge for Health (K4Health) Project based at Johns Hopkins Bloomberg School of Public Health's Center for Communication Programs. She has a Master of Health Science from Johns Hopkins Bloomberg School of Public Health with a concentration in women's and reproductive health.

Sara Mazursky is an eLearning Coordinator with the K4Health Project based at Johns Hopkins University Center for Communication Programs. She is devoted to reproductive and women's health advocacy and has a Master of Public Health from the University of North Texas Health Science Center.

Kavitha Nallathambi is a Communications Specialist with the K4Health Project based at Johns Hopkins University Center for Communication Programs. She is devoted to utilizing innovative communication channels to deliver evidencebased information. She has a Master of Science in Development Studies from the London School of Economics and Political Science.

\section{Need for eLearning in less developed countries}

The World Health Organization (WHO) estimates that "the world faces a shortage of 4.3 million health professionals required for delivering essential health care services to populations in need" (Taylor, Hwenda, Larsen, \& Daulaire, 2011, p. 2348). Nowhere is the need for trained health workers greater than in Africa, where "for more than 900 million people, there are fewer than 500 full-time [health] staff...Over half $(55 \%)$ of countries do not have any postgraduate public health programme" (IJsselmuiden, Nchinda, Duale, Tumwesigyed, \& Serwaddad, 2007, p. 914). Trained health professionals include the gamut of health care professionals from doctors, nurses, midwives, and community health workers to program managers and policy makers leading and influencing health programs and policies.

In an analysis of the global workforce, the Joint Learning Initiative- a consortium of more than 100 health leaders - suggested that strengthening human resources for health is crucial for building sustainable health systems. Building the knowledge base and increasing opportunities for continuous learning were cited as two of the main ways to strengthen the workforce and health system (Chen et al., 2004).

The field of technology-enabled learning offers a flexible and sustainable approach to training and continuous learning, especially when it is part of a comprehensive capacity building strategy. The field of technology-enabled learning has long been characterized by a plethora of terms and strategies. Some strategies include distance learning, blended learning, computer-based/online learning, synchronous (realtime) and asynchronous (self-paced) group and individual eLearning courses - all of which can be mutually reinforcing. In this paper, the authors use the term, eLearning, in its narrowest sense to refer to asynchronous, individual computer-based training. 
Asynchronous, individual eLearning courses can be updated easily and can quickly communicate state-of-the-art technical and programmatic information.

Research has shown that eLearning increases opportunities for continuous learning, which leads to improved knowledge and skills and professional growth of health professionals. A large meta-analysis of studies conducted between 1990 and 2007 involving learners in the health professions found that Internet-based instruction is associated with favorable outcomes across a wide variety of learners, learning contexts, clinical topics, and learning outcomes. Internet-based instruction appears to have a large effect compared with no intervention and appears to have an effectiveness similar to traditional methods (Cook, Levinson, Garside, \& Dupras, 2008). This finding was supported by an evaluation of an eLearning model focused on respiratory infection control for front-line health care workers in Kenya. eLearners and classroom-trained groups experienced almost identical knowledge gains (Centers for Disease Control, 2010). Similarly, in the Gambia, Community Health Nurses (CHNs) piloted a computer-based training (CBT) package as part of a malaria in-service training program. The CBT package was well received, with all respondents either strongly agreeing or agreeing that the CBT package was helpful. Learners reported increased confidence and the desire for more computer instruction (Dawson \& Joof, 2005).

Despite the successes described above, several significant barriers exist when developing and implementing eLearning programs in less developed countries. Lack of infrastructure for information and communication technologies (ICT) and inadequate computer skills among the population impede the development of successful eLearning programs in many countries (Alam, Kabir, \& Elizabeth, 2006). However, with the swift and widespread increase in Internet and computer access globally (World Internet Usage, 2011) these obstacles are rapidly growing smaller. An eLearning model developed for an African context noted that eLearning can overcome barriers to educational access as long as the model is, "sensitive to the level of availability of infrastructure, [and has] technical support, [a] clear policy on implementation, evaluation and curriculum re-orientation" (Omwenga, Waema, \& Wagacha, 2004, p. 34).

By enabling training to take place in the daily working environment rather than on-site, eLearning facilitates an applied mode of professional development that can respond directly to the requirements of health systems at the local level (Joynes, 2011). Thus, eLearning can be used to increase opportunities for continuous learning among public health professionals and increase knowledge and skills of health workers in a country. Cook et al. (2008) research that computer-assisted instruction is neither inherently superior nor inferior to traditional methods supports this claim. However, Cook et al. (2008) also notes that the magnitude of benefit for certain learning outcomes, such as skills development and patient-provider interaction, was small and few nonInternet comparison studies reported skills and behavior or patient effects outcomes. Therefore, additional research is needed in this area.

With funding from the United States Agency for International Development (USAID), the Knowledge for Health (K4Health) Project, based at Johns Hopkins Bloomberg School of Public Health's Center for Communication Programs (JHU.CCP), has developed, implemented, and evaluated several asynchronous eLearning initiatives in the last decade. The K4Health Project uses eLearning to strengthen the capacity of public health practitioners and institutions in two ways. First, K4Health works with subject matter experts in a variety of global health technical areas to develop their capacity to create asynchronous eLearning courses that are intended to improve the knowledge and comprehension skills of health professionals around the world. The platform on which 
these courses are hosted, the Global Health eLearning (GHeL) Center, is K4Health's longest running eLearning activity and demonstrates the use of eLearning for individual level capacity building.

Second, K4Health builds organizational capacity to initiate comprehensive eLearning activities through the development and integration of asynchronous eLearning courses into broader capacity building and training activities. K4Health trains staff within partner organizations to plan, develop, manage, monitor and evaluate eLearning activities. This approach increases capacity of organizations to provide continuous training and mentoring of staff and others and ensures that eLearning activities are responsive and relevant to on-the-ground realities of public health training in various organizations and geographic locations.

This paper will describe K4Health's successes and lessons learned from using these two different but complementary approaches to capacity building for eLearning. Specifically, K4Health's experience building individual level capacity via GHeL courses and building organizational and country level capacity in South Africa, Nigeria, and Bangladesh will be discussed.

\section{Global Health eLearning Center}

\subsection{Background}

In early 2000s, the United States Agency for International Development (USAID) received inquiries from their field staff about a better way to access up-to-date technical public health information. In 2005, USAID identified eLearning as a cost-effective solution to meet this growing demand and contracted Management Sciences for Health (MSH) to develop a custom eLearning platform, called the Global Health eLearning (GHeL) Center, for use in settings with low-bandwidth Internet connectivity.

The GHeL Center presents asynchronous Internet-based courses that provide useful and timely continuing education for health professionals. Courses offer state-ofthe-art technical content on key public health topics, including country examples and case studies to stimulate thinking about ways in which the learner can use the information covered in the course to solve problems in the field. GHeL courses are free and can be accessed 24 hours a day from any place in the world via the Internet. Courses are designed to be taken online at the learner's own pace and completed in approximately two hours. The courses include pre- and post-test quizzes and a final exam that tests learners' knowledge of the subject matter. A learner can earn a certificate of completion after scoring $85 \%$ or higher on the final exam. Learners can also download course materials or print portions of the course or the entire course for further study. Although asynchronous eLearning limits real-time interactions with peers and instructors and makes assessing transfer of knowledge and skills difficult, it enables a large number of learners to participate from any location and at a time when it is most convenient for them.

Once learners register on the GHeL site, they can access fifty courses in nine certificate programs, representing different technical and programmatic areas. As of April 2012, the certificate programs include:

- Child Survival

- Family Planning and Reproductive Health 
- Gender and Health

- Health Systems

- HIV/AIDS

- Infectious Diseases

- Maternal Health

- Neonatal Health

- Cross-Cutting Topics (such as the management of logistics and commodities for health, environmental issues, and health systems strengthening, which apply across one or more technical areas in health sector)

Since its inception, K4Health has designed courses and trained other health professionals to develop courses on the GHeL platform. Because the courses are standalone and self directed, they can be easily incorporated into an organization's or country's multi-pronged capacity building strategy for improving the knowledge and skills of its staff or local workforce.

Originally developed as a resource for USAID field staff, 1,390 learners were registered on the site in its first year (2005). Due to unanticipated demand, the GHeL courses have expanded to reach beyond its original audience of USAID field staff to other health professionals living and working in developing countries. Six years later, the GHeL main audience has shifted to non-USAID health professionals who make up more than $80 \%$ of learners. By 2011, a total of 92,418 users from around the world have registered (see Fig. 1: Registered Learners by Year (2005-2011)) and earned over 100,000 certificates. The number of registered learners, certificates earned, and available courses have grown at a rapid rate despite the fact that GHeL partners have not widely promoted the platform or individual courses, indicating the unprecedented demand and importance of these courses.

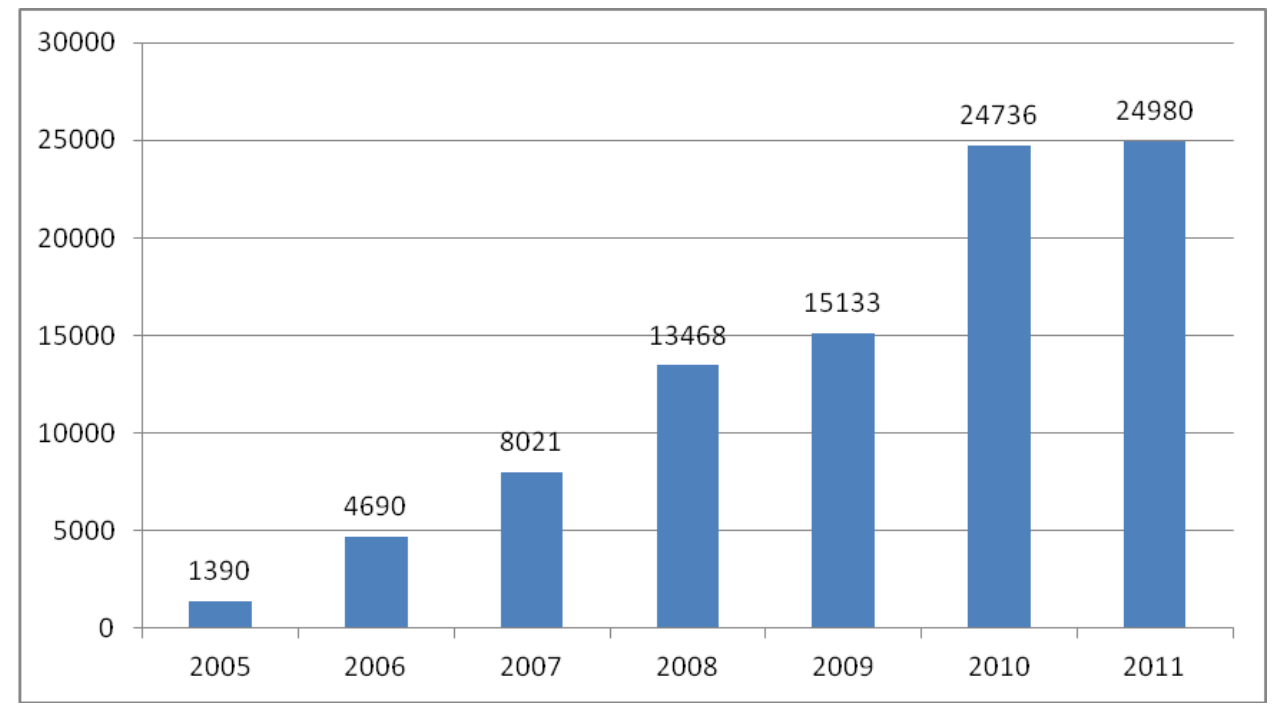

Fig. 1. Registered learners by year (2005-2011) 


\subsection{Evaluation of the Global Health eLearning Center}

From 2010 to 2011, K4Health conducted the first comprehensive evaluation of GHeL to determine its reach, use, and usefulness. The evaluation took place in three phases.

In the first phase, K4Health enlisted Cekan Consulting to analyze GHeL registration and data from course evaluation reports from October 2005 to April 2010. Although Cekan Consulting found that the GHeL Center is a leader in transferring evidence-based knowledge to learners in developing countries, GHeL falls short in measuring the actual application of knowledge gained from courses.

K4Health began phase two of the evaluation to address the shortcoming described above. K4Health conducted an online survey to better evaluate learners' application of knowledge gained from GHeL courses. The survey was disseminated to all learners who accessed the GHeL Center between March 1, 2010 and February 28, 2011, including those who completed a course and those who started but did not complete a course. The survey asked about usability (e.g. overall satisfaction, additional features preferred), relevancy (e.g. usefulness, specific needs to localize course), and use of knowledge (e.g. information use, results, increased knowledge on topics).

Phase three aimed to further explore uptake and acquisition of new information and application of knowledge among learners. This phase consisted of in-depth interviews with a sample of learners who had successfully completed a course in the previous year; that is, those who had scored $85 \%$ or higher on a course final exam. K4Health conducted 26 interviews by telephone and email in August and September 2011

\subsection{Key findings from the evaluation of the Global Health eLearning Center}

At the time of Cekan Consulting's analysis (April 20, 2010), GHeL had 50,197 registered learners from 184 countries. During the four-and-a-half year study period, 53,268 certificates were earned by 15,245 .

Of the top 30 countries represented by learners earning certificates for successful completion of a GHeL course, most learners were located in sub-Saharan Africa, followed by Europe/North America, and Asia (see Fig. 2: Location of Learners from the Top 30 Countries Earning Certificates). Learners from Nigeria, the US, and Kenya received the largest number of certificates $(6,137$ total), amounting to $40 \%$ of all learners. Interestingly, learners from countries in crisis, such as Afghanistan, Haiti, Pakistan, Somalia, Sudan, and Zimbabwe, were among the top 30 countries earning certificates. 


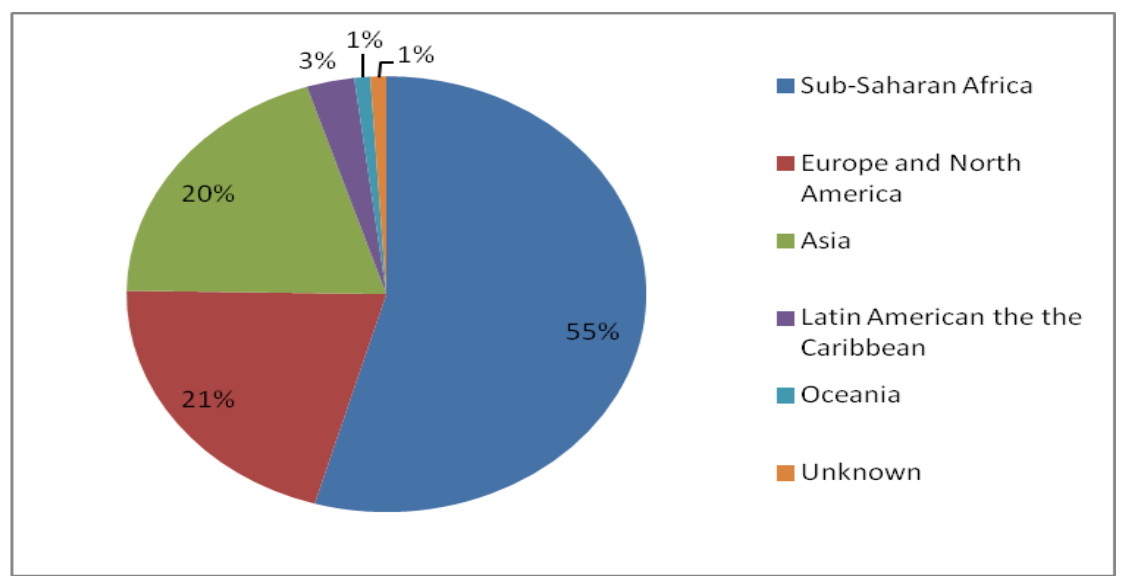

Fig. 2. Learners from the Top 30 countries earning certificates ( $n=13,493$ learners)

At the time of the evaluation, programmatic health professionals were the largest group of learners earning certificates from the GHeL Center. Students, clinicians and academics were the next largest groups (Fig. 3: Percentage of Learners Earning Certificates by Profession). One interesting finding was that two-thirds of all clinical learners earning certificates were from Africa.

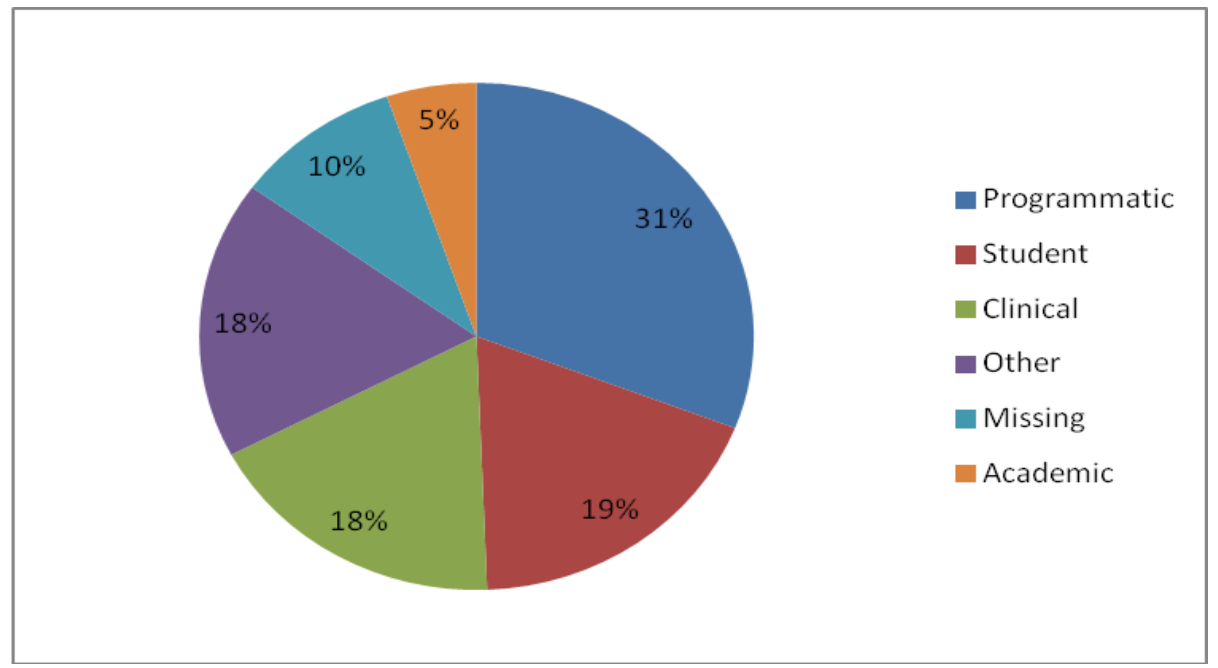

Fig. 3. Percentage of learners earning certificates by profession $(n=15,245)$

The demographic findings on regional distribution and occupational differences reveal GHeL's widespread reach in transferring evidence-based knowledge to learners in developing countries. The success in reaching its target audience of health professionals (specifically program managers) in developing countries while investing in very limited promotional efforts is seen in these data. The differences in regional distribution and occupation can be attributed to a need for information in the technical areas of GHeL courses, a convenient alternative to traditional learning for busy health professionals, or a free resource to which the target audience might not otherwise have access. 
From course evaluation reports, the majority of learners felt that the course enabled them to learn at their own pace and the knowledge they gained from the course was worth the time it took to complete it. Among learners who scored $85 \%$ or higher on course final exams, self-reported satisfaction was high to very high. However, many online survey respondents (70-85\%) desired the ability to receive mentoring from an expert and the ability to interact online with a subject matter expert during a course.

A large percentage of online survey respondents $(76 \%)$ said that wanting to gain technical knowledge for use in their current job was a main reason for them to take a specific course. Many in-depth interview respondents saw the courses not only as valuable sources of knowledge, but as a main source of current technical health information. Interviewees often took a course to learn new skills, such a monitoring and evaluation. In addition, many respondents in the in-depth interviews reported that they took courses to address a specific programmatic issue such as integrating HIV with family planning and child survival. One respondent said "I am the training coordinator and I need basic information, or updated information on all the areas that we cover, HIV being part of it..." (HIV Basics Part 1 course learner, Uganda). Interest in identifying best practices for replication and management skills were also noted as reasons for taking a course. One respondent said, "I am working in Public Health and Management Field as well as I am a medical doctor, therefore, this course helped me in better management of tasks within my current job and can help me take part in the development of my country" (FP Legislative and Policy Requirements course learner, Afghanistan).

In-depth interviews showed that learners applied the knowledge gained from successfully completing in a number of ways. The most frequently mentioned ways of using the information gained were by developing, updating, implementing, and evaluating programs and plans, using information for meetings and conferences, developing guides and handouts for health and social workers, and for advocacy efforts. Most individuals recommended and shared information from courses with colleagues and staff to increase skills and knowledge within and outside their organizations.

Among online survey respondents who started but did not finish a course, $22 \%$ said that it was difficult to access a computer with an Internet connection and $14 \%$ said that they could not afford Internet access to finish the course. This finding was further supported in interviews with eLearning experts that Cekan Consulting conducted to gather information on the effectiveness of eLearning in global health. Interviewees from five international public health organizations revealed that consistent and affordable Internet access remains a challenge to implementing eLearning programs in Africa and Asia.

While it is often taken as a given that most people would prefer eLearning courses adapted to their language and local context, in-depth interview respondents did not agree on this issue. Those who worked for country governments preferred global perspectives and standards, whereas those from non-governmental organizations (NGOs) said that translation to local languages and inclusion of country-specific case studies were essential. NGO workers further noted that translation to local languages and inclusion of culturally relevant examples is key to implementation, program improvement, and knowledge enhancement. Audiences identified for localized courses included community health workers, surveillance officers, and nurses. 


\section{From global level to country level}

As the evaluation of GHeL showed, this eLearning activity has been tremendously successful in transferring current, evidence-based health information to over 51,000 learners in 184 countries. While continuing to build capacity of individual public health professionals via GHeL, K4Health wanted to increase the impact of its eLearning activity by increasing capacity of organizations to implement their own eLearning activities.

K4Health developed a capacity building program that includes minimal face-toface training, extensive virtual training, and tools to plan, design, implement, monitor and evaluate a range of eLearning activities. K4Health's first use of this program took place in Southern Africa in 2010. Building on its experience in Southern Africa, K4Health began working with local partners in Nigeria and Bangladesh in 2011 to implement eLearning activities.

\section{Southern Africa regional activities (2010-2012)}

The Southern Africa region has been severely devastated by the HIV/AIDS epidemic. The region has a mostly generalized epidemic, driven by high levels of multiple and concurrent sexual partnerships, and exacerbated by weak health care systems and a severely depleted health care workforce.

K4Health is building the capacity of strategic regional organizations (e.g., Southern Africa HIV and AIDS Information Dissemination Service (SAfAIDS)) to strengthen sustainable, regional HIV knowledge management systems. K4Health is strengthening regional capacity to capture, organize, synthesize, adapt, share, and use relevant HIV information through support and training of partners of the United States President's Emergency Plan for AIDS Relief (PEPFAR) and other key regional stakeholders. To maximize the impact of the project and to ensure sustainability, K4Health is also strengthening and supporting national level HIV information and knowledge management systems within the national governments, including National AIDS Commissions.

With technical assistance from K4Health, SAfAIDS planned to use eLearning to support regional and national level knowledge exchange around HIV in three ways: (1) supplement two days of a face-to-face workshop; (2) complement other knowledge sharing products, such as online toolkits which are collections of expert-vetted resources; and (3) provide access to a wide range of HIV-specific, asynchronous eLearning courses through a single community portal. The target audience for these eLearning activities included local organizations in the Southern Africa region working on HIV prevention at local, regional and country levels, such as NGOs, advocacy and community-based organizations, and service providers.

To house these courses, toolkits, and other resources, K4Health developed Southern Africa HIV AIDS Resource Exchange (SHARE; http://www.hivsharespace.net/), a regional Web-based portal for capturing HIV/AIDS information and promoting knowledge exchange. This virtual space provides a platform where health and HIV-focused professionals can access eLearning courses, online toolkits, information centers and related literature and connect with one another, seek answers to technical questions, and contribute their own knowledge for others to access.

The first eLearning course that SAfAIDS developed was Documentation and Communication of Best Practices for HIV/AIDS Programmes. SAfAIDS adapted the 
content of this course from an existing curriculum for a face-to-face workshop. They pilot tested the course and launched online and offline versions. The offline CD-ROM versions were used in South Africa, Zimbabwe, and Swaziland by users with low to no Internet connectivity. SAfAIDS then developed a course titled, Traditional Leaders Championing $H I V$ and Gender Based Violence (GBV) Prevention and began working on a third course, Integrating Lesbian, Gay, Bisexual, Transgender, Intersex (LGBTI) Issues into HIV and GBV Prevention.

The Documentation and Communication of Best Practices for HIV/AIDS Programmes and Traditional Leaders Championing HIV and Gender Based Violence $(G B V)$ Prevention have recently been launched online and are currently being actively promoted by SAfAIDS. The evaluation plan for these courses focuses on their reach and usefulness as described by learners. Reach will be captured by the learning management system, while an online survey will assess learners' levels of satisfaction and intended use of knowledge from the courses.

\section{Nigeria's web-based continuing professional development program (2011-2013)}

As Africa's most populous country - the seventh most populous in the world and expected to pass 170 million in 2012-Nigeria has faced considerable challenges in addressing the needs of a population that grows at an annual rate of over $2.5 \%$ (CIA World Factbook, 2012). While Nigeria's 3.6\% HIV-positive prevalence rate is comparatively low among African countries, the sheer volume of population means that around 3 million people in Nigeria currently live with HIV, with over 330,000 new infections being reported each year (UNAIDS, 2010). Because laboratory testing is the cornerstone of diagnosing and treating HIV, strengthening laboratory systems, infrastructure, and personnel is necessary to achieve universal access to care and treatment.

The K4Health/Nigeria Web-based Continuing Professional Development (CPD) Program is a two-year project providing opportunities for Medical Laboratory Scientists to continuously improve their knowledge, update and sharpen old skills, and acquire new ones. Continuing professional development is one of the strategies for continuous quality improvement of Clinical and Public Health Laboratory services. However, currently, Medical Laboratory Scientists in Nigeria have minimal opportunities for updating their knowledge and skills throughout their careers. Having access to a Web-based CPD program could significantly improve the ability of Medical Laboratory Scientists to deliver accurate and reliable laboratory test results.

The K4Health/Nigeria Web-based CPD Program, a USAID-funded project, is responding to this need. The K4Health Project works closely with and supports the Medical Laboratory Science Council of Nigeria (MLSCN) and the Association of Medical Laboratory Scientists of Nigeria (AMLSN) in the development, implementation, and institutionalization of the Web-based CPD program. K4Health is building the capacity of AMLSN - both the capacity of its individual members as well as the capacity of the organization - to develop, manage, and monitor an eLearning program. K4Health is also working with MLSCN to draft, implement, and monitor an updated CPD policy that will institutionalize the use of CPD credits within the country, ensuring that all Medical Laboratory Scientists participate in CPD activities to keep their technical knowledge and skills current. By the end of the project, at least $50 \%$ of Medical 
Laboratory Scientists in Nigeria will earn a CPD credit from the MLSCN through the K4Health/Nigeria Web-based CPD program.

At the start of the project, a number of assessments were conducted with the target audience and with partners. These assessments ensured that Medical Laboratory Scientists were interested in a Web-based CPD program and refined the technical areas they wanted to update and their preferred methods of information delivery. Assessments also confirmed that partner organizations were ready to participate in this initiative.

In an effort to overcome the issue of access to the Internet based CPD program, MLSCN and AMLSN purchased computer equipment that will be made available to Medical Laboratory Scientists who visit their central offices in Nigeria's capital. In addition, partners will produce and disseminate a limited number of CD-ROMs to Medical Laboratory Scientists working in areas with limited to no Internet connectivity. However, local partners decided to require the Scientists to complete the final exams of all courses online. Not only is this standard practice for test taking in Nigeria, but the partners wanted to deter cheating and ensure more accurate record keeping.

The success of this program will primarily be measured by at least $50 \%$ of Medical Laboratory Scientists in Nigeria (approximately 8,500) earning a CPD credit through the K4Health/Nigeria Web-based CPD program. In order for this to be possible, K4Health must increase the organizational capacity of AMLSN to develop, launch, and monitor its own eLearning courses and assist MLSCN with revising, institutionalizing, and monitoring an updated policy making CPD credits a requirement of licensure renewal. The program will also assess whether knowledge and skills of Medical Laboratory Scientists have improved through online surveys and focus groups. This program will provide evidence in a short period of time as to the feasibility and effectiveness of introducing eLearning courses as part of a CPD program for a large group of health professionals. This evidence will help local partners improve and expand the Web-based CPD program.

\section{Bangladesh knowledge management initiative ( 2011-2013)}

Bangladesh is one of the world's most populated countries with approximately 148 million people, making it the seventh largest population in the world (World Bank, 2010). It is a densely-populated country that has made major strides over the past decade to curb population growth and improve the health of its people. In recent years, maternal and child mortality substantially declined. However, Bangladesh remains one of the world's poorest nations with approximately half the population living on less than $\$ 1$ per day, and a gross national income of $\$ 700$ per capita (World Bank, 2010). The nation's population is poised to reach 250 million by 2075 , and the nation is struggling to meet the health and development needs of its existing population let alone the future needs of this growing population.

With a vision of achieving a healthy, happy population progressing towards a middle-income country, the Government of Bangladesh (GOB) developed a national strategic plan: the Health, Population and Nutrition Sector Development Program (HPNSDP) for 2011-2016. This plan has identified a package of essential services for family planning, maternal, newborn and child health, and nutrition interventions that must be scaled up to achieve the GOB's objectives.

In order to begin making progress towards these objectives, health workers especially those at the community and household level - need to update their training so 
that they can communicate effectively and provide integrated services that holistically address the health, family planning, and nutritional needs of a family.

The Bangladesh Knowledge Management Initiative (BKMI) is developing an eLearning program that aims to increase the knowledge and skills of community health care workers, educators and other health influencers for the effective delivery of essential health services called for in the Government of Bangladesh's Health, Population and Nutrition Sector Development Program. Knowledge and skills gained by community healthcare workers, educators, and other health influencers will aim to improve the adoption of healthier behaviors by families and communities, and increase utilization of healthcare services, ultimately improving overall health and well-being.

BKMI is developing eLearning courses for low-literate health workers at the community level, such as Family Welfare Volunteers, Family Welfare Assistants, Health Education Officers, Community Health Care Providers, and other Outreach Workers through Upazila Health Clinics, Union Family Welfare Centers, and Community Clinics.

To develop the eLearning courses, K4Health works closely with specific units within the GOB, having a technical advisor located in three key units to support coordination of behavior change communication, provide capacity building through technical assistance, and assist with designing and implementing all aspects of this Initiative. This model builds capacity of in-country stakeholders from the start through the end of the project, ensuring a country-led, sustainable initiative.

The three technical advisors, counterparts in the GOB, and their partners will conduct a pre-assessment to capture current gaps in knowledge, comprehension and application of FP, MNCH, and nutrition among community health care workers, educators and other influencers as well as their skills and gaps in technology-based modes of delivery for learning. The results from the pre-assessment will inform course development, dissemination, and the course platform.

The team began designing eLearning curricula around three priority health areas family planning, maternal and child health, and nutrition with an integrated health focus that includes key elements of effective interpersonal communication principles. The courses will combine current technical content with instructional design elements, best practices, and case studies from Bangladesh.

Ultimately, the eLearning program will consist of eight courses that are easily accessible in low- or no-bandwidth settings, will offer a platform to host eLearning courses in Bangla; will train course authors to create their own courses; and will build capacity of in-country staff of public and private agencies to build and manage eLearning courses.

In an effort to overcome issues of access, the eLearning courses will be made available at resource centers through 300 computers in existing district, upazila and union health or information centers through CD-ROM, DVDs or flash drives, and through 300 netbooks to community health workers without access to computer-equipped health centers.

The purpose of the BKMI eLearning courses is to increase the knowledge and skills of community healthcare workers, educators and other health influencers about the effective delivery of essential health services. Success will be measured by the number of health workers visiting and successfully completing the courses. In addition, BKMI is going to conduct a pilot "Certification" program to assess knowledge, comprehension, and application of knowledge among learners. BKMI will review client-provider 
interactions prior to and following completion of the eLearning courses, and based on its findings, along with results of self-assessments and supervisory reviews of selfassessments, award certification of knowledge gained by community healthcare workers. Depending on resource availability, BKMI is considering using mobile phones to assess the potential impact of the "Certification" program on client-provider interactions by surveying community members through voice messages.

The country-owned approach being led by the Government of Bangladesh with technical assistance from K4Health will not only build capacity of frontline health workers, but will also strengthen the capacity of information exchange specialists within the GOB's Directorate General of Family Planning and the Bureau for Health Education in the Directorate General of Health.

\section{Lessons learned}

From its experience managing the Global Health eLearning Center and country programs in Southern Africa, Nigeria, and Bangladesh, K4Health has learned much about building capacity among individuals and organizations for implementing eLearning activities. These lessons learned are described below.

\subsection{Individual-level capacity building}

\subsubsection{Language of eLearning courses is context specific}

When deciding if course content should be in English or another local language, it is important to consider the target audience's literacy and education levels and course development resources. Based on these two factors, K4Health has created courses only in English; however, the courses in the Southern Africa and Nigeria project include culturally and locally relevant content written by local partners. In Bangladesh, the courses are being developed in English first, and then being translated into Bangla since the target audience is less educated cadres of healthcare providers who do not speak or read English. Language of courses also largely depends on the individuals writing the course. For example, if course authors are more comfortable speaking and writing in a local language, it may be best to present the course in their native language.

\subsection{2. eLearning can be successfully incorporated into broader learning programs}

A key feature of many eLearning courses, such as the ones on the GHeL Center, is that they can be easily incorporated into blended learning approaches. For example, the GHeL course titled, Geographic Approaches to Global Health, was a prerequisite to an incountry Geographic Information Systems (GIS) training workshop that took place in Rwanda. This asynchronous course was used as pre-training to an in-country workshop to ensure that all workshop participants arrived with a minimum level of understanding of the key concepts so that more in-person time could be spent on more complex topics. Similarly, in South Africa, SAfAIDS plans to use its Documentation and Communication of Best Practices for HIV/AIDS Programmes course as a complement to an in-person training, which will allow them to shorten a face-to-face training workshop from five to three days. 
As described earlier, the eLearning activities in Nigeria and Bangladesh are one component of larger programs in the country. Nigeria's Web-based courses are part of a larger CPD program that will build capacity of Medical Laboratory Scientists. In Bangladesh, courses are part of a larger initiative to deliver coordinated, integrated, and harmonized communication and knowledge management that motivates healthier population, health, and nutrition behaviors and increases use of health services among communities.

The incorporation of asynchronous eLearning courses into blended learning strategies mutually reinforces learning outcomes.

\subsubsection{Evaluating "success" of an eLearning program at the individual level can be challenging}

There is no uniform definition of "success" in an in eLearning program. Evaluating the "success" of an eLearning program largely depends on the specific objectives of a particular eLearning activity and on the project's budget. A project's budget can heavily influence the scope of evaluation activities and therefore affect its definition of success. At a minimum, data on knowledge and comprehension should and can be easily collected through quizzes and exams. Ultimately, K4Health is interested in better understanding the impact not only on learners' knowledge and skills, but how this impact translates into improved practices and contributes to improvements in client outcomes. This type of $\mathrm{M} \& \mathrm{E}$ is more costly and complex. Due to resource constraints, most eLearning activities are restricted in terms of the scope and evaluation of eLearning activities.

As described earlier, K4Health aims to use reach, usefulness, and use as indicators of success. These indicators, defined and described in the Guide to Monitoring and Evaluation of Health Information Products and Services, correspond nicely to the first three levels of Kirkpatrick's Learning Evaluation Scale ${ }^{1}$, which are:

- Level 1: Reaction $=$ To what degree participants react favorably to the training;

- Level 2: Learning = To what degree participants acquire the intended knowledge, skills, attitudes, confidence, and commitment based on their participation in a training event;

- Level 3: Behavior = To what degree participants apply what they learned during training when they are back on the job; and

- Level 4: Results = To what degree targeted outcomes occur as a result of the training event and subsequent reinforcement.

Measuring results usually requires time delay and enlisting the feedback of an objective supervisor; this level of measurement is not often undertaken. Measuring reach, usefulness, and use can be challenging in and of themselves and should be planned for from the start of the project.

\footnotetext{
${ }^{1}$ Developed by Donald Kirkpatrick in 1967, Kirkpatrick's four levels of evaluation can be used to help evaluate training programs. Evaluation should begin at level 1 and feed into evaluations at higher levels. Evaluations at each level become more difficult but provide more information (Kirkpatrick, 1994).
} 


\subsection{Organizational-level capacity building}

\subsubsection{Capacity can be increased using a variety of mechanisms}

K4Health uses a mix of face-to-face trainings, virtual mentoring, and provision of resources to build eLearning capacity of organizations. For the Southern Africa Regional eLearning Activities, a staff member was temporarily relocated to Pretoria, South Africa to coordinate eLearning and other activities. For the Nigeria project, US-based eLearning specialists make periodic, short visits to meet local stakeholders, obtain and sustain their buy-in and train local staff. The close collaboration and ownership of the project by the local partners has been paramount to the program's initial progress and ultimate success.

In Bangladesh, the Government of Bangladesh (GOB) is providing technical assistance and capacity building through Technical Advisors for Knowledge Management and Communication who are placed within the different units responsible for family planning, maternal and child health and nutrition. The Advisors support the units in identifying, collecting, synthesizing, managing and applying knowledge and information for the development of more effective, coordinated and integrated behavior change communication and health intervention delivery at all levels and across multiple sectors.

As these examples demonstrate, different methods can be used to build capacity. Being flexible, responsive to partners, and aware of available resources will help an organization choose the best methods for each situation.

\subsubsection{Evaluating "success" of strengthening eLearning capacity at an organizational level can be challenging}

K4Health has typically determined success based on completion of training staff, helping that organization create a sustainability plan for its eLearning activities, and whether the organization has continued eLearning activities.

However, an explicit objective in the second year of the Nigeria project is to count the number of eLearning courses a local partner organization develops with limited-to-no technical assistance from K4Health. The solo completion of courses by this organization will indicate that K4Health was successful in building eLearning capacity of that organization.

\section{Next steps}

K4Health has developed eLearning programs at the global and country levels that are helping to not only build the individual capacity of public health professionals around the world, but also to build the organizational capacity of institutions interested in employing eLearning as one of its approaches to training.

In recent years, K4Health has made eLearning a component of a broader blended learning approach within its own organization as well as those in which we work. This creates a more robust and sustainable eLearning program and keeps learners more engaged. Also, weaving eLearning into a robust training and skill development strategy helps sustain eLearning activities. 
There are continual challenges to implementing and evaluating eLearning activities - especially in less developed countries - including ICT infrastructure, computer and Internet access, language issues, and definitions of success. However, the rapid rise in Internet access and the great interest in eLearning and mobile technology for health (mHealth) suggest that these challenges will lessen over time.

As K4Health expands its country-level eLearning activities, it is also incorporating different technologies in its eLearning portfolio. In a 2010 pilot project in Malawi, K4Health and partners used district learning centers coupled with an SMS system to provide access to and promote the use of information for family planning/reproductive health and HIV/AIDS to improve service delivery.

During this pilot project, partners established two district learning centers with 11 computers that have been visited by more than 5,000 people to receive basic computer training, search for medical information, access eLearning courses, and print health information resources. More than 663 mobile phones and solar chargers were distributed to community health workers. Those workers sent more than 1,000 SMS messages about family planning and HIV/AIDS to the district hub and the district management team sent twice as many messages to the workers. The mobile phone network has provided prompt responses to emergencies, for example, high-risk pregnancies, and outbreaks such as measles, subsequently saving lives.

The Malawi pilot project is encouraging as it used different modes of technology to reach a population that is not usually targeted in eLearning programs - rural community health workers with little access to the Internet. K4Health plans to expand upon this pilot project by joining together best practices in developing eLearning programs with best practices in mHealth.

KHealth has made great strides in developing individual and organizational capacity in eLearning expanding the reach, usefulness, and use of its programs over time. The future holds even greater potential to address human resource issues and expand reach through rapid developments in technology and its utilization. As eLearning programs grow and expand, so too will our ability to capture the success of these programs through our monitoring and evaluation efforts.

\section{Acknowledgements}

K4Health is supported by the Office of Population and Reproductive Health, Bureau for Global Health, U.S. Agency for International Development under the terms of grant number GPO-A-00-08-00006-00. The views expressed in this document do not necessarily reflect those of the U.S. Agency for International Development or of the U.S. government.

\section{References}

Alam, M. J. B., Kabir, S. M., \& Elizabeth, H. (2006). e-Learning in Bangladesh: Implementation and evaluation of a pilot project. In Proceedings of MMT 2006, Finland. Retrieved from http://www.codewitz.net/papers/MMT 77-82_eLearning_in_Bangladesh.pdf.

Centers for Disease Control. (2010). Breathing easier: CDC introduces e-learning technology to help prevent hospital-associated infections. CDC Global Health EBrief, 1st Quarter 2010. 
Chen, L., Evans, T., Anand, S., Boufford, J. I., Brown, H., Chowdhury, M., Cueto, M., Dare, L., Dussault, G., Elzinga, G., Fee, E., Habte, D., Hanvoravongchai, P., Jacobs, M., Kurowski, C., Michael, S., Pablos-Mendez, A., Sewankambo, N., Solimano, G., Stilwell, B. de Waal, A., \& Wibulpolprasert, S. (2004). Human resources for health: overcoming the crisis. Lancet, 364, 1984-1990.

CIA World Factbook. (2012). Africa: Nigeria. Retrieved from https://www.cia.gov/library/publications/the-world-factbook/geos/ni.html.

Cook, D., Levinson, A., Garside, S., \& Dupras, D. (2008). Internet-based learning in the health professions: A meta-analysis. JAMA, 300(10), 1181-1196. doi:10.1001/jama.300.10.1181

Dawson, A. J., \& Joof, B. M. (2005). Seeing, thinking and acting against Malaria: A new approach to health worker training for community empowerment in rural Gambia. Rural and Remote Health, 5(4), 353.

IJsselmuiden, C. B., Nchinda, T. C., Duale, S., Tumwesigyed, N. M., \& Serwaddad, D. (2007). Mapping Africa's advanced public health education capacity: the AfriHealth project. Bulletin of the World Health Organization, 85(12), 914-922.

Joynes, C. (2011). Distance learning for health: What works. A global review of accredited post-qualification training programmes for health workers in low and middle income countries. London International Development Center. Retrieved from http://www.lidc.org.uk/ assets/DL4H\%20Report\%20Full.PDF.

Kirkpatrick, D. L. (1994). Evaluating training programs. San Francisco: Berrett-Koehler Publishers, Inc.

Omwenga, E. I., Waema, T. M., \& Wagacha, P. W. (2004). A model for introducing and implementing e-learning for delivery of educational content within the African context. African Journal of Science and Technology (AJST) Science and Engineering Series. 5(1), 34-46.

Taylor, A. L., Hwenda, L., Larsen, B.-I., \& Daulaire, N. (2011). Stemming the brain drain - A WHO global code of practice on international recruitment of health personnel. N Engl J Med. 365, 2348-2351.

UNAIDS. (2010). United Nations general assembly special session country progress report - Nigeria, p. $16 . \quad$ Retrieved from http://data.unaids.org/pub/Report/2010/nigeria_2010_country_progress_report en.pdf.

World Bank. (2010). World development indicators online. Retrieved from http://data.worldbank.org/indicator.

World Internet Usage. (2011). Internet world stats. Retrieved from http://www.internetworldstats.com/stats.htm. 